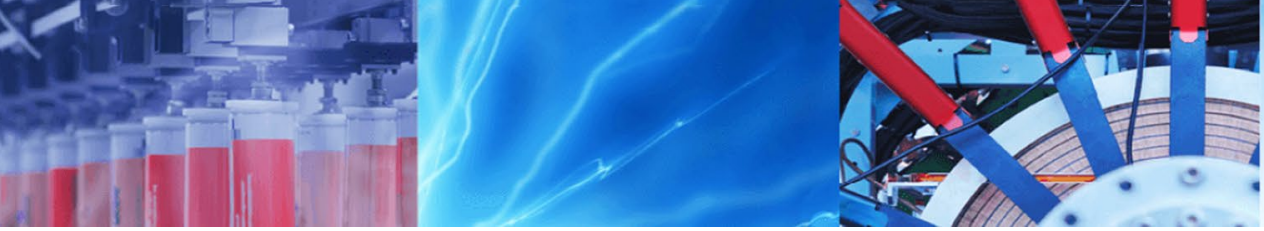

Research Article

\title{
Alternative mathematical modeling for plastic hinge of reinforced concrete beam
}

\author{
Mohamed A. Farouk ${ }^{1} \cdot$ Khaled F. Khalil ${ }^{1,2}$
}

Received: 5 September 2019 / Accepted: 13 November 2019 / Published online: 19 December 2019

(c) Springer Nature Switzerland AG 2019

\begin{abstract}
The presentation of the plastic zone for flexural members is basic as it administrates the load carrying and deformation capacities of the member. Therefore, plastic hinge study has been of great attention to structural researchers for decades. The behavior of plastic hinge is very tricky due to the high nonlinearity of materials, and relative movement between the component materials and strain localization. As a result, most researchers investigated the problem experimentally or by using programs which depend on the materials nonlinearity such as ANSYS, ABAQUS or ADINA programs. This paper tries to investigate the problem analytically by proposing a simple approximate equation to compute the plastic hinge rotation. A lot of parameters such as the tension and compression steel ratios, concrete strength, steel yield, section geometry and the load position were considered in the suggested equation. The analytical results of simply supported beams under middle concentrated load with different parameters were presented and compared with the conjectures of the various formulations, software programs (ANSYS and NONLACS2) and experimental results. The simplified suggested equation gave satisfying results. Moreover this paper presented a structural mathematical model based on the suggested equation to predict the deformations behavior of the beams. The plastic rotation and deflections can be predicted by the mathematical model after yielding till the failure moment, not only at the failure moment as in the common formulations. The mathematical model was verified and gave values of deflections matching experimental results.
\end{abstract}

Keywords Plastic hinge $\cdot$ Mathematical model $\cdot$ Plastic rotation $\cdot$ R.C beams

\section{Introduction}

The plastic hinge in which the plastic deformation localized in a small zone is critical for flexural members as it controls the load carrying and deformation capacities of the member. The important gain of including the inelastic behavior of the members in structural design is that the moment redistribution which occurs can increase appreciably the strength of the structure above the strengths calculated by the elastic theory. The inelastic behavior of Reinforced Concrete (RC) sections leads to a redistribution of moments and forces, resulting in an increased load carrying capacity of the members and the indeterminate structure. As the applied load is increased, hinges start forming in succession at locations where the hinge moment capacity is reached; with further increase in the applied load, these hinges continue to rotate until the last hinge forms converting the structure into a mechanism resulting in failure. The plastic rotation capacity is a complex issue, mainly because of interaction of the various parameters such as materials, member geometry, loading type. Due to the large variation of these factors experimental results from previous research show significant scatter of the measured values of rotation capacity. Various formulations given by Baker and Amarakone [4], Mattock (1966), Corley [11] and Riva and Cohn [21] were performed

Mohamed A. Farouk, moh.anour@yahoo.com; Khaled F. Khalil, khaled_lashen1@yahoo.com | ${ }^{1}$ Civil Engineering Department, Delta University for Science and Technology, Talkha, Egypt. ${ }^{2}$ Civil Engineering Department, Zagazig University, Zagazig, Egypt. 
to predict the plastic rotation capacity. A parametric study is performed by Kheyroddin and Naderpour [2] to assess the influence of the tension reinforcement index, and the bending moment distribution (loading type) on the ultimate deformation characteristics of reinforced concrete (RC) beams, the analytical results for 15 simply supported beams with different amounts of tension reinforcement ratio under three different loading conditions are presented and compared with the predictions of the various formulations and the experimental data. Ko et al. [17] descript an experimental study on the plastic rotation capacity of reinforced high strength concrete beams, they tested thirty-six beams with various compressive strengths of concrete, tensile reinforcement ratios and loading type to evaluate the plastic rotation capacity and compared the experimental data with numerical analysis. A lot of research can be carried out in the effect parameters on the plastic rotation capacity such as steel ratios and size effects. It has for instance been suggested by Hilierbogr $[14,15]$, and Markeset [16]. that the rotation capacity of plastic hinges is member size dependent, approximately inversely proportional to the beam height. Some experimental work in this field has been done in the past, where such a tendency has noticed Mattock [18], Corley [11], Cederwall and Sobko [10] and Bosco et al. [6]. Bigaj and Walraven [1] proceeded test series on simply supported slender beams to study the size effect on the rotation capacity of plastic hinges; they descript a model for the rotation capacity. Many experimental and theoretical studies have been conducted to examine the ductile behavior and plastic rotation of reinforced high-strength concrete beams Arslan and Cihanli [3], Bernardo and Lopes [5] and Carmo and Lopes $[7,8]$. The studies generally showed the high-strength concrete members have sufficient ductility to guarantee their structural safety provided that an appropriate choice of the amount and location of the reinforcement is made, and that the general rules adopted for normal-strength concrete structures can also be applied to high-strength concrete structures.

\section{Various previous formulations to compute plastic rotation capacity}

For the loading type of concentrated load at mid span, the most widely used $\theta_{p}$ formulations in Europe and North American are presented as follows

\section{Baker and Amarakone [4]}

$\theta_{p}=0.8\left(\varepsilon_{u}-\varepsilon_{c y}\right) k_{1} k_{3}\left(\frac{z}{d}\right)$ $\varepsilon_{c u}=0.0015\left(1+150 \rho_{s}+\left(0.7-10 \rho_{s}\right) \frac{d}{c}\right)$,

where $k_{1}=0.7$ for mild steel or 0.9 for cold-worked steel, $k_{3}=0.6$ when $f_{c}^{\prime}=35.2 \mathrm{MPa}$ or 0.9 when $f_{c}^{\prime}=11.7 \mathrm{MPa}$, $z=$ distance of critical section to the point of contraflexure, $d=$ effective depth of member, and $c=$ the neutral axis depth at the ultimate moment.

\section{Mattock [19]}

$\theta_{p}=\left(\varphi_{u}-\varphi_{y} \frac{M_{u}}{M_{y}}\right)\left(1+\left(1.14 \sqrt{\frac{z}{d}}-1\right)\left(1-\frac{\omega-\omega \prime}{\omega_{b}}\right) \sqrt{\frac{d}{16.2}}\right) \frac{d}{2}$

$\varepsilon_{c u}=0.003+\frac{0.5}{z}$

where $\varphi_{u}=$ ultimate curvature, $\varphi_{y}=$ yield curvature, $\omega=$ tension reinforcement index, $\omega^{\prime}=$ compression reinforcement index, $\omega_{b}=$ balance reinforcement index.

\section{Corley [11]}

$\theta_{p}=\left(\varphi_{u}-\varphi_{y} \frac{M_{u}}{M_{y}}\right)\left(1+\frac{0.4}{\sqrt{d}}\right)\left(\frac{d}{2}\right)$

$\varepsilon_{u}=0.003+0.02 \frac{b}{z}+\left(\frac{\rho_{s} f_{y}}{20}\right)^{2}$

Riva and Cohn [21]

For $\frac{\varphi_{u}}{\varphi_{y}} \leq 7, \quad \theta_{p}=\left(0.58-\frac{3}{800 \omega}\right)\left(\frac{\varphi_{u}}{\varphi_{y}}\right)^{0.9} \varphi_{u} z$

For $\frac{\varphi_{u}}{\varphi_{y}}>7 \quad \theta_{p}=\left(\frac{5}{100}+\frac{6.5}{1000} \frac{\varphi_{u}}{\varphi_{y}}\right) \varphi_{u} z$

\section{Analytical solution}

\subsection{The materials modeling}

1. Concrete constitutive model

Numerous stress-strain curve equations have been developed. Some equations are shown as follows.

Smith and Young [23]

$f=f_{c}^{\prime}\left(\frac{\varepsilon}{\varepsilon_{0}}\right) \exp \left(1-\frac{\varepsilon}{\varepsilon_{0}}\right)$ 
where $f=$ stress at any strain, $f_{c}^{\prime}=$ maximum stress, $\varepsilon=$ strain $\varepsilon_{0}=$ strain at the maximum stress.

Desayi and Krishnan [12]

$f=\frac{E \varepsilon}{1+\left(\frac{\varepsilon}{\varepsilon_{0}}\right)^{2}}$

where $\mathrm{E}=\mathrm{a}$ constant (same as initial tangent modulus).

Carrerira and Chu [9], Ezeldin and Balaguru [13], Nataraja et al. [20]

$\frac{f}{f_{c}^{\prime}}=\frac{\beta\left(\frac{\varepsilon}{\varepsilon_{0}}\right)}{\beta-1+\left(\frac{\varepsilon}{\varepsilon_{0}}\right)^{\beta}}$

where $\beta=\frac{1}{1-\frac{f_{c}^{\prime}}{\varepsilon_{0} E_{i t}}}$ for $\beta \geq 1.0, \varepsilon \leq \varepsilon_{u^{\prime}} E_{i t}$ is the initial tangent modulus.

In this analytical model, the concrete constitutive model will be represented by dividing the stress strain curve of concrete into two parts; the first part is ascending branch and will be represented as in Eq. (12) proposed by Saenz [22]

$\sigma=\frac{E_{0} \varepsilon}{1+\left(\frac{E_{0}}{E_{s c}}-2\right)\left(\frac{\varepsilon}{\varepsilon_{\max }}\right)+\left(\frac{\varepsilon}{\varepsilon_{\max }}\right)^{2}}$

where $E_{s c}$ is the secant modulus of elasticity at the peak stress $E_{0}$ is the initial modulus of elasticity and $\varepsilon_{\max }$ is the strain at peak stress. The stress in the second part of the curve is assumed constant with increasing the strain.

\section{Reinforcement steel modeling}

The reinforcement steel will be modeled as an elastic strain-hardening material as shown in Fig. 2.

\subsection{The curvature after yielding}

For the reinforced concrete section after cracks till yielding, the compression stress in concrete can be assumed linearly, but after the yielding where starting the formation of plastic hinge, the concrete stress transforms nonlinearly, and the equilibrium equations become more difficult. Based on the assumed stress-strain relationships of the concrete and steel reinforcement as shown in Figs. 1 and 2 , and assuming that plane sections remain plane after bending the strain diagram over the section will be linear as shown in Fig. 3. The section will be divided into small segments. These segments have equally height as a

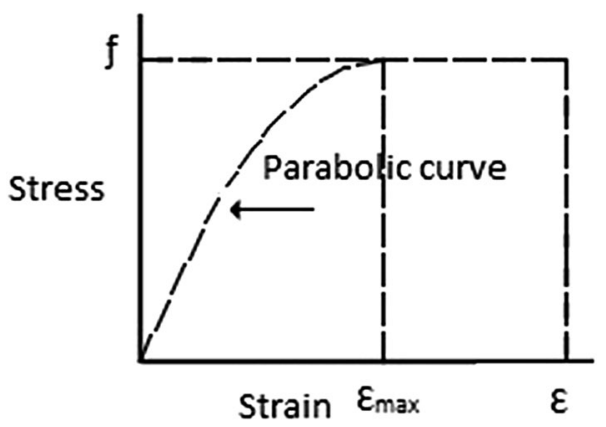

Fig. 1 Concrete modeling

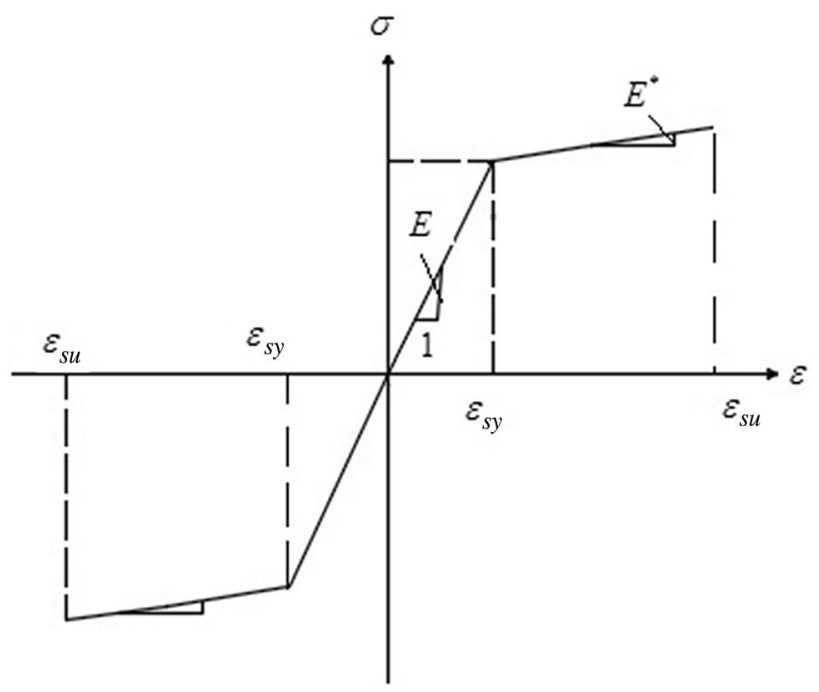

Fig. 2 Reinforced steel modeling

ratio of the depth of compression zone $(\phi c)$. For arbitrary value for concrete strain after yielding $\left(\varepsilon_{c}\right)$, and according to Eq. (12), the stresses distribution over the section after yielding can be determined and predicated as shown in Fig. 3. The equilibrium equations will be as follows:

$A_{s} f_{y}+A_{s} E^{*}\left(\varepsilon_{c} \frac{d-c}{c}\right)-A_{s} E^{*} \varepsilon_{y}=\lambda c+A_{s}^{\prime} f_{s}^{\prime}$

$A_{s}\left(f_{y} c+E^{*} \varepsilon_{c} d-E^{*} \varepsilon_{c} c-E^{*} \varepsilon_{y}\right)=\lambda c^{2}+A_{s}^{\prime} f_{s}^{\prime} c$

$c=\frac{-\xi+\sqrt{\xi^{2}-4 \lambda \psi}}{2 \lambda}$

where

$\xi=\left(A_{s}^{\prime} f_{s}^{\prime}+A_{s}\left(\varepsilon_{c} E^{*}-f_{y}+E^{*} \varepsilon_{y}\right)\right.$

$\psi=-A_{s} E^{*} \varepsilon_{c} d$ 
Fig. 3 Stress and strain distribution of a reinforced concrete section
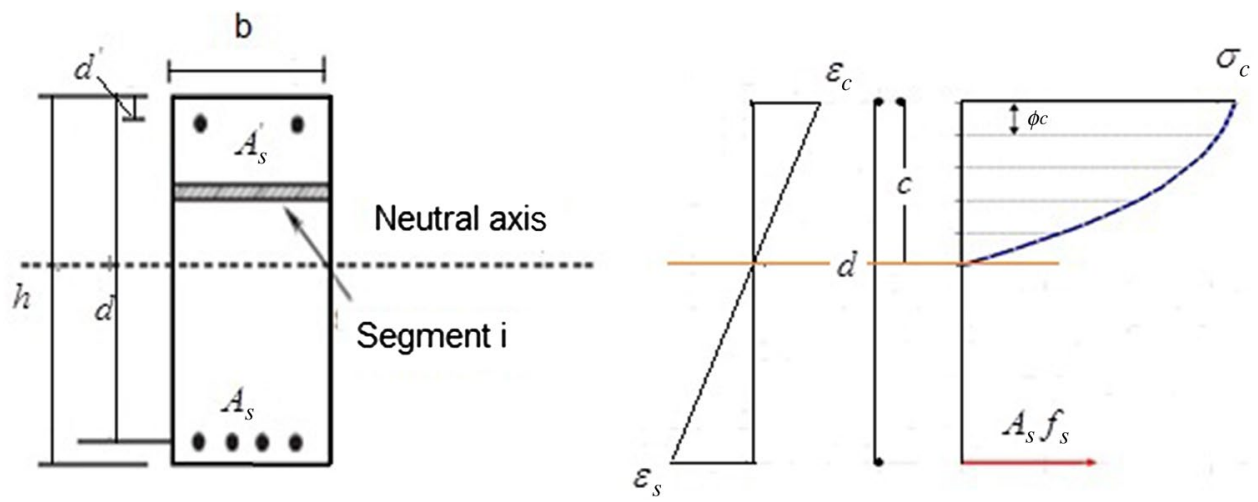

$\lambda=\frac{\phi b}{2}\left(\sigma+2 \sum_{N=0.1}^{0.9}\left(\sigma_{N}\right)\right)$

where $\mathrm{N}=0.1,0.2,0.3, \ldots 0.9, \phi$ is the ratio of segment height to the depth of neutral axis from compression fiber (c), in the current analysis $\phi$ is assumed to equal to 0.1 .

$$
\begin{gathered}
\sigma=\frac{E_{0} \varepsilon_{c}}{1+\left(\frac{E_{0}}{E_{s c}}-2\right)\left(\frac{\varepsilon_{c}}{\varepsilon_{\max }}\right)+\left(\frac{\varepsilon_{c}}{\varepsilon_{\max }}\right)^{2}} \\
\sigma_{N}=\frac{(N) E_{0} \varepsilon_{c}}{1+\left(\frac{E_{0}}{E_{s c}}-2\right)\left(\frac{(N) \varepsilon_{c}}{\varepsilon_{\max }}\right)+\left(\frac{(N) \varepsilon_{c}}{\varepsilon_{\max }}\right)^{2}}
\end{gathered}
$$

For example, $\sigma_{N=0.1}=\frac{0.1 E_{0} \varepsilon_{c}}{1+\left(\frac{E_{0}}{E_{s c}}-2\right)\left(\frac{0.1 \varepsilon_{c}}{\varepsilon_{\max }}\right)+\left(\frac{0.1 \varepsilon_{c}}{\varepsilon_{\max }}\right)}$

$\varepsilon_{s}^{\prime}=\varepsilon_{c} \frac{c-d^{\prime}}{c}$

If $\varepsilon_{s y} \geq \varepsilon_{s^{\prime}}^{\prime} f_{s}^{\prime}=E_{s} \varepsilon_{s}^{\prime}$

$\varepsilon_{s y}<\varepsilon_{s^{\prime}}^{\prime} \quad f_{s}^{\prime}=f_{y}+E_{s}^{*}\left(\varepsilon_{s}^{\prime}-\varepsilon_{y}\right)$

The bending moment which is corresponded to the assumed value of concrete strain can be calculated as follows:

$$
\begin{aligned}
M= & \phi b c\left(\frac{\sigma+\sigma_{0.9}}{2}\right)(c-0.5 \phi c)+\phi b c\left(\frac{\sigma_{0.9}+\sigma_{0.8}}{2}\right)(c-1.5 \phi c) \\
& +\phi b c\left(\frac{\sigma_{0.8}+\sigma_{0.7}}{2}\right)(c-2.5 \phi c)+\cdots
\end{aligned}
$$

The bending moment can be formulated as

$M=\frac{\phi b c^{2}}{2}\left[\sigma(1-0.5 \phi)+\sum_{N=0.1}^{0.9} 2 \sigma_{n}(1-10 N \phi)\right]+A_{s}^{\prime} f_{s}^{\prime}\left(d-d^{\prime}\right)$
Hence, for any arbitrary value of concrete strain $\left(\varepsilon_{c}\right)$ after yielding, the values of $\mathrm{c}$ and $\mathrm{M}$ can be found according to Eqs. (15)-(25).

The curvature at any stage of loading after the yield can be calculated as the following equation

$\varphi=\frac{\varepsilon_{c}}{c}$

At the ultimate moment

$\varphi_{u}=\frac{\varepsilon_{c u}}{c_{u}}$

where $\varepsilon_{c u}$ the concrete strain at ultimate moment, $c_{u}$ the depth of compression zone at ultimate moment.

At the yield moment

$\varphi_{y}=\frac{\varepsilon_{c y}}{c_{y}}$

where $\varepsilon_{c y}$ the concrete strain at yield moment, $c_{y}$ the depth of compression zone at yield stage can be calculated based on linear analysis by solving the following equation

$\frac{b}{2} c_{y}^{2}+n\left(A_{s}-A_{s}^{\prime}\right) c_{y}-n\left(A_{s}^{\prime} d^{\prime}+A_{s} d\right)=0$,

where $\mathrm{n}$ the modular ratio

$\varepsilon_{c y}=\varepsilon_{s y} \frac{c_{y}}{d-c_{y}}$

\subsection{Plastic rotation capacity}

Values of concrete strain can be assumed in-between the two values $\varepsilon_{c u}$ and $\varepsilon_{c y}$. From Eqs. (15), (25) and (26), the 
curvature and its corresponding moments can be calculated. At the ultimate load stage, the real distribution of curvature can be idealized into elastic and plastic regions as shown in Fig. 4.

Thus the total rotation $\left(\theta_{\text {total }}\right)$ over the beam length can be divided into elastic $\left(\theta_{e l}\right)$ and plastic $\left(\theta_{p l}\right)$ rotations. The elastic rotation which is defined until the first yielding of steel can be obtained using the curvature at yielding. The plastic hinge rotation $\left(\theta_{p l}\right)$ on each side of the critical section shown in Fig. 4, can be defined as:

$\theta_{p}=\int_{0}^{I_{y}}\left(\varphi(x)-\varphi_{y}\right) d x$

In which, $l_{y}$ is the beam length over which the bending moment is larger than the yielding moment (My) or the distance between the critical section and the location where tension steel bars start yielding and $\varphi(x)$ is the curvature at a distance $x$ from the critical section at the ultimate load stage. The shaded area in Fig. $4 \mathrm{c}$ shows the plastic rotation $\left(\theta_{p l}\right)$ that occurred in addition to the elastic rotation at the plastic hinge at the ultimate load stage.

\subsection{Simplified equation for computing plastic rotation capacity}

Five simply supported beams subjected to middle concentrated load will be analyzed by the analytical solution

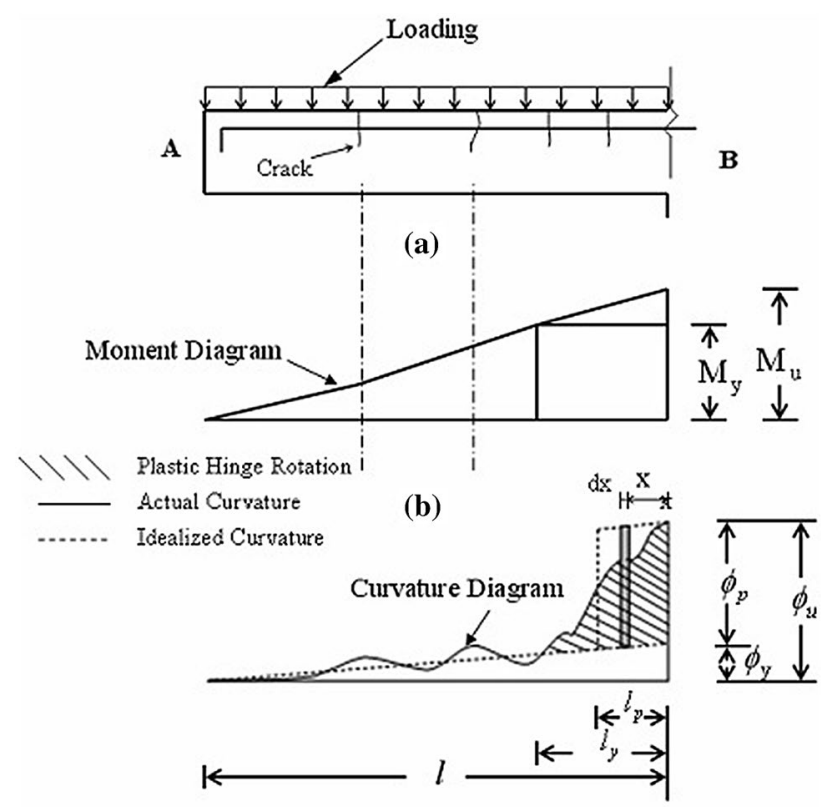

(c)

Fig. 4 The curvature and the bending moment of cantilever beam to compute the plastic hinge rotation, the steel reinforcement ratio was variable for these beams.

The details of these beams are as shown in Fig. 5 and Table 1.

The curvature of the analyzed beams was computed by using Eq. (26). Figure 6a-e show the curvature through the half span of the beams.

The plastic rotation can be computed according to Eq. (31). The beams curvature will be linearly before yielding zone and it transformed to curve shape through the yield length, this curve decreases as the steel ratio increases. Generally, the curve intensity of the curvature through the yield zone was small for all beams and the curvature can be considered linearly through the yield length. Thus, the equation of computing the plastic rotation at the ultimate moment can be simplified as follows:

$\theta_{p u}=\frac{1}{2}\left(\varphi_{u}-\varphi_{y}\right) l_{y}$

$I_{y}$ depends on the load typing, in the present case $I_{y}=\frac{M_{u}-M_{y}}{M_{u}}$

$\theta_{p u}=\frac{L}{4}\left(\varphi_{u}-\varphi_{y}\right) \frac{M_{u}-M_{y}}{M_{u}}$

\subsection{Comparison of the plastic rotation capacity between the Suggested equation in the present study and various formulations}

A paramedic study was performed by Kheyroddin and Naderpour [2] to study the influence of the tension

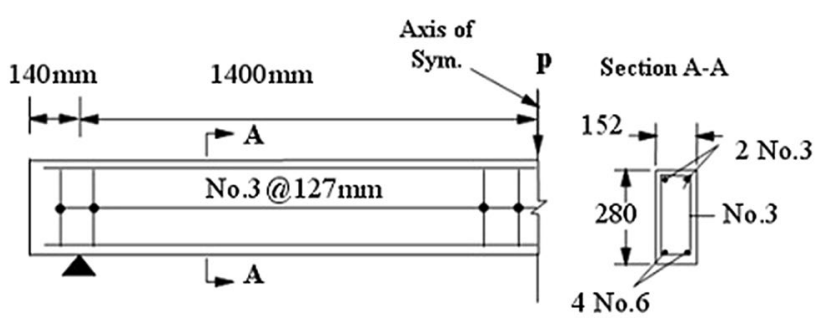

Fig. 5 Geometry and reinforced details of beam 5

Table 1 Details of the analyzed beams

\begin{tabular}{llllll}
\hline Beam & $\rho=A_{s} / b d$ & $f_{c}^{\prime}(\mathrm{MPa})$ & $f_{y}(\mathrm{MPa})$ & $\rho^{\prime}$ & Type of loading \\
\hline 1 & 0.0294 & 23.4 & 328 & 0.0037 & Concentrated load \\
2 & 0.022 & 23.4 & 328 & 0.0037 & Concentrated load \\
3 & 0.0147 & 23.4 & 328 & 0.0037 & Concentrated load \\
4 & 0.011 & 23.4 & 328 & 0.0037 & Concentrated load \\
5 & 0.0074 & 23.4 & 328 & 0.0037 & Concentrated load \\
\hline
\end{tabular}




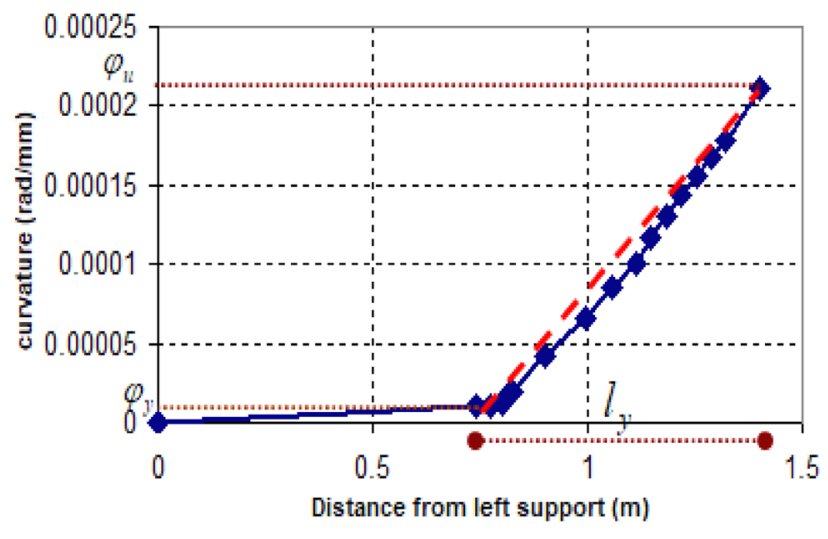

(a) Beam 1

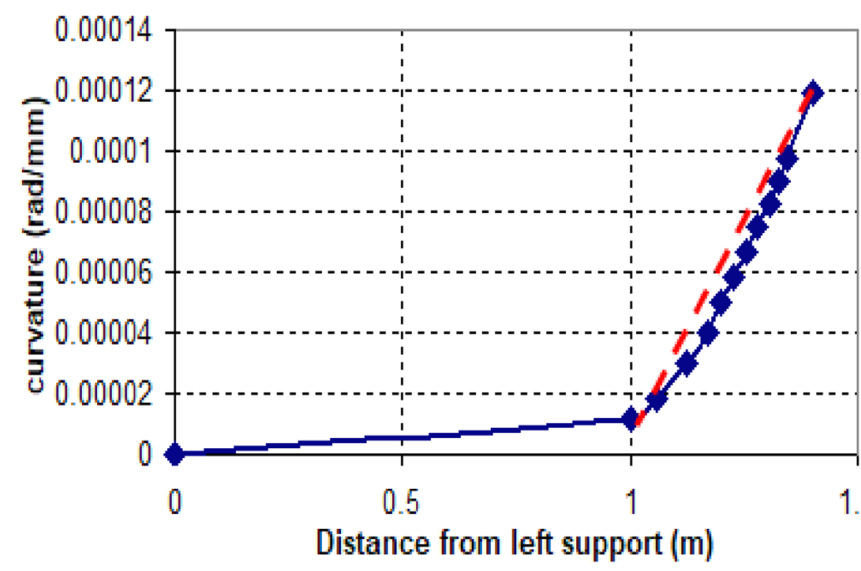

(c) Beam 3

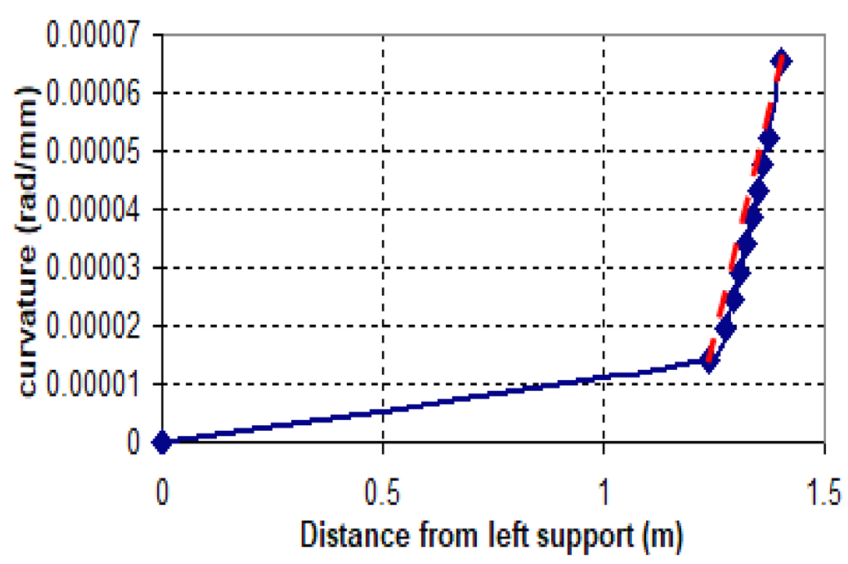

(e) Beam 5

Fig. 6 The curvature of the analyzed beams

reinforcement as one parameter on the ultimate deformations of (RC) beams. The details of these beams are as shown in Fig. 6. They analyzed these beams by finite element method by using NONLACS2 (NONLinear Analysis of Concrete and Steel Structures). Plastic rotations and

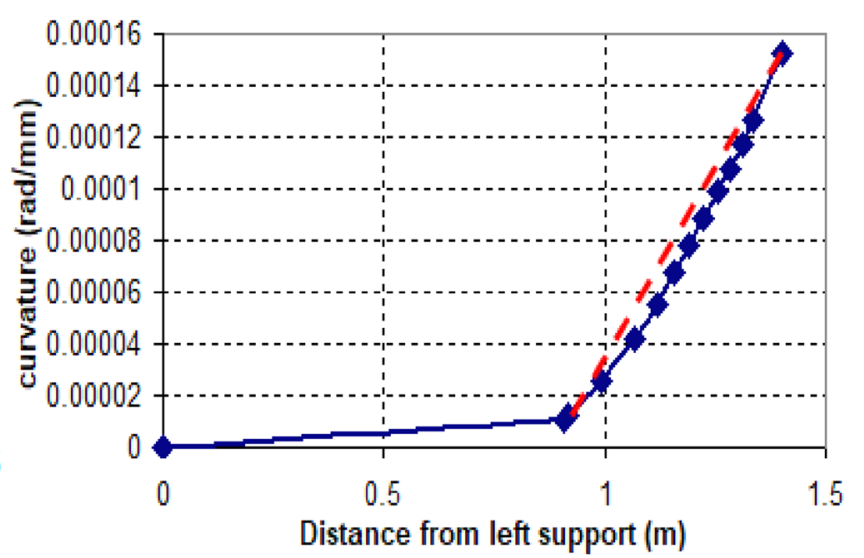

(b) Beam 2

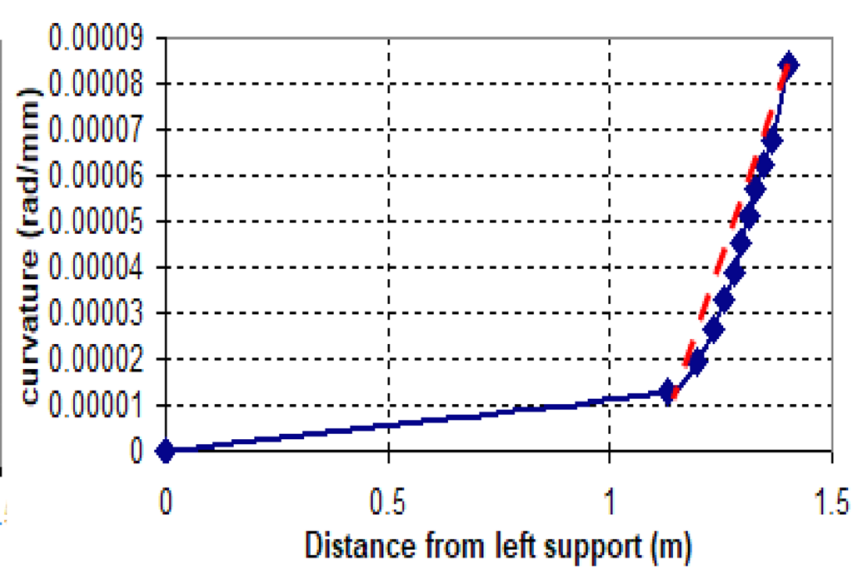

(d) Beam 4

\section{SN Applied Sciences}

curvature ductility factor of these beams were computed and compared with Baker and Amarakone [4], Mattock [18] and Corley [11] formulations.

The plastic rotation capacity will be computed for the same beams by the simplified Eq. (33), by using ANSYS 
Fig. 7 The elements in ANSYS program

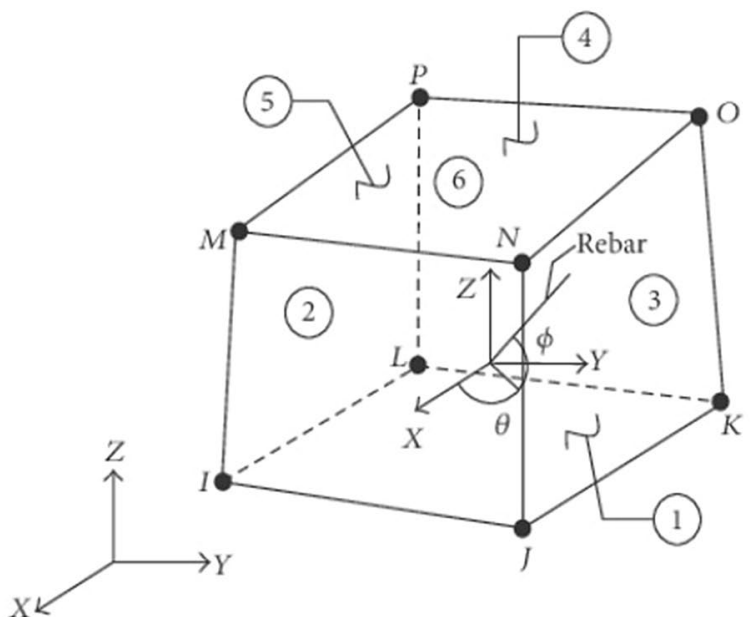

(a) Solid 65-3D

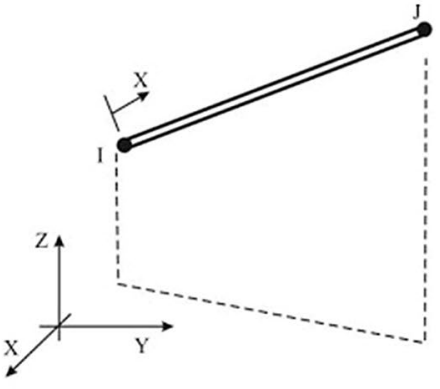

(b) 8-3D bar element.

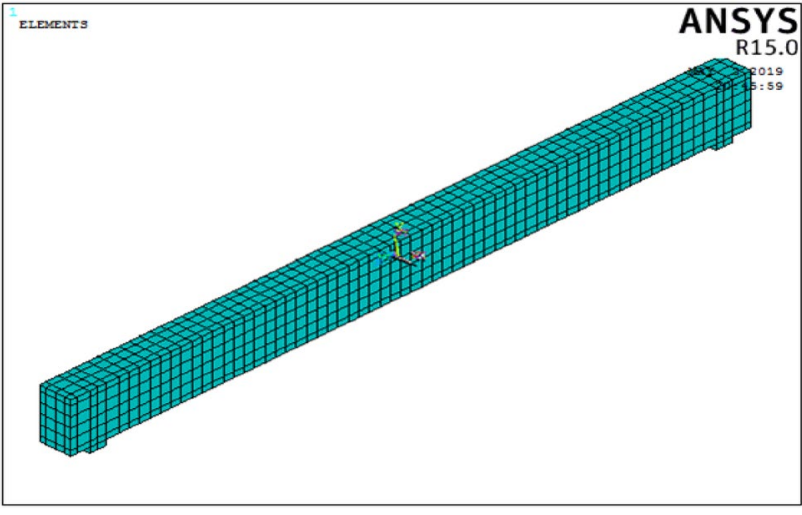

Fig. 8 Beam modeling in ANSYS program

program, and will be compared with the results of the various formulations. Beam modeling in ANSYS program.

Solid65, an eight node solid element, is used to model the concrete with or without reinforcing bars. The solid element has eight nodes with three degrees of freedom. The element is capable of having plastic deformation, cracking in three orthogonal directions, and crushing. The geometry and node locations for this element type are shown in Fig. 7a.

The reinforcement has been modeled as a discrete reinforcement (Link8) throughout the element (solid65). concentrated loads; the purpose of this case shows how to use the suggested model to calculate the deformations after occurring the plasticity as shown in Figs. 8, 9.

It was observed from the comparison of curvature ductility factor in Fig. 10b, that the analytical results were close to the values obtained from Corley formulation, NonLAAC2 and ANSYS programs, but Mattock equation gave a high values. Also, Fig. 10a illustrates that as the

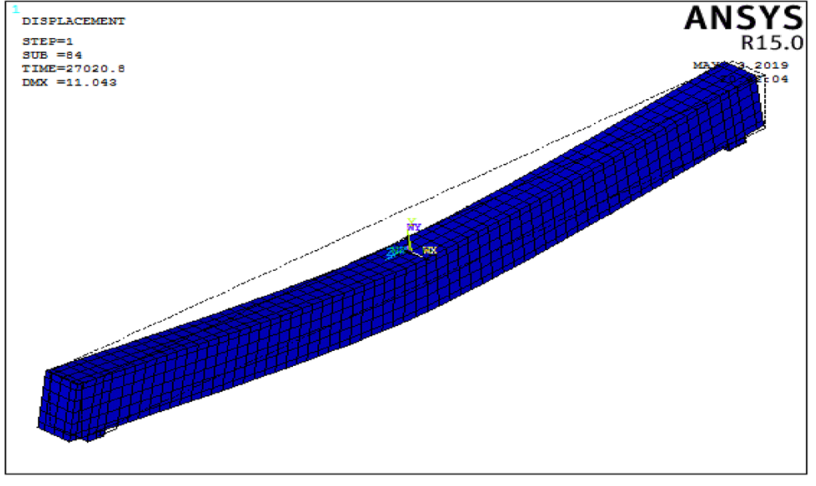

Fig. 9 Deformations of the beam

steel ratio increases; there is a convergence in the plastic rotation between the simplified equation and the various presented formulations. For steel ratio greater than 0.015 , the simplified suggested equation gave a fairly values of plastic rotation close to the results of Corley equation, NonLAAC2 and ANSYS programs. But the Baker and Mattock equations gave far values. For steel ration equal to 0.0074 , the values of plastic rotation diverged between the simplified equation and the other methods.

\subsection{Verified the suggested simplified equation experimentally}

Ten simply supported beams under middle concentrated load were tested by Bigaj and Walraven [1] to cover the investigation of three major parameters effect (member size, steel ratio and concrete type) on the plastic rotation capacity. The details of these beams are shown in Fig. 11 and Table 2. By using the simplified suggested equation, 


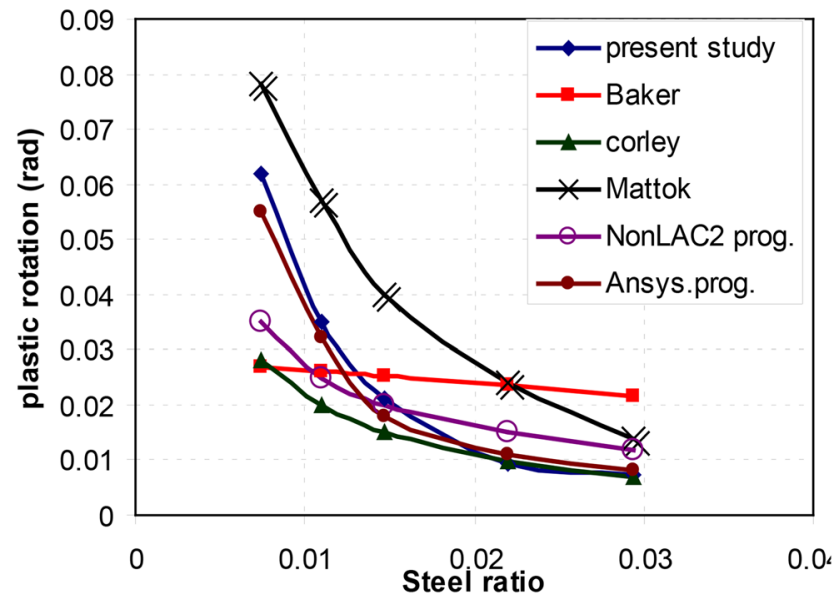

(a) Plastic rotation

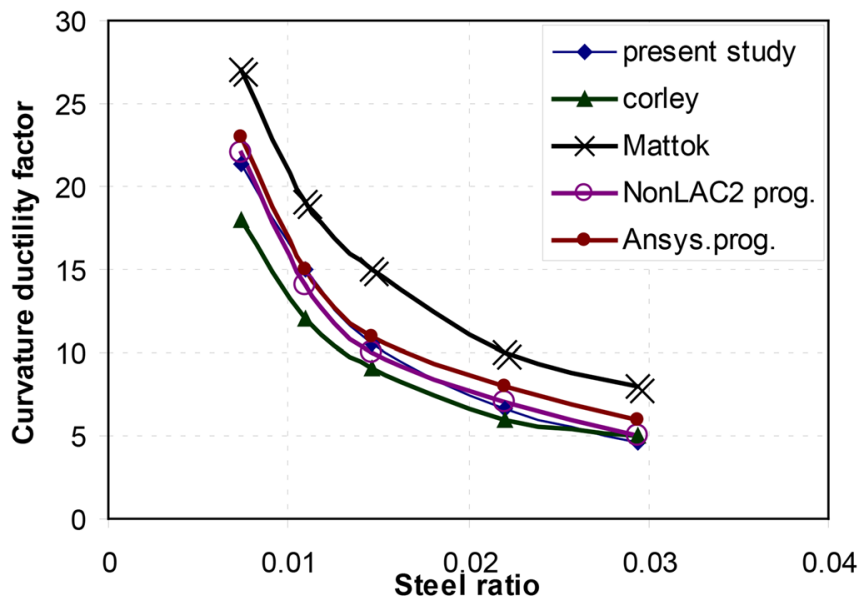

(b) Curvature ductility factor

Fig. 10 Plastic rotation and curvature ductility factor

Fig. 11 Geometry of tested specimens

Table 2 Characteristics of the test specimens
Specimen B.0.1

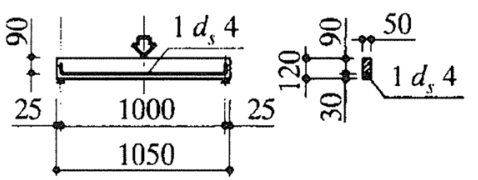

Specimen B.0.2

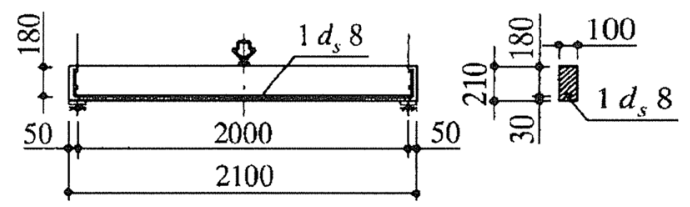

Specimen B.0.3

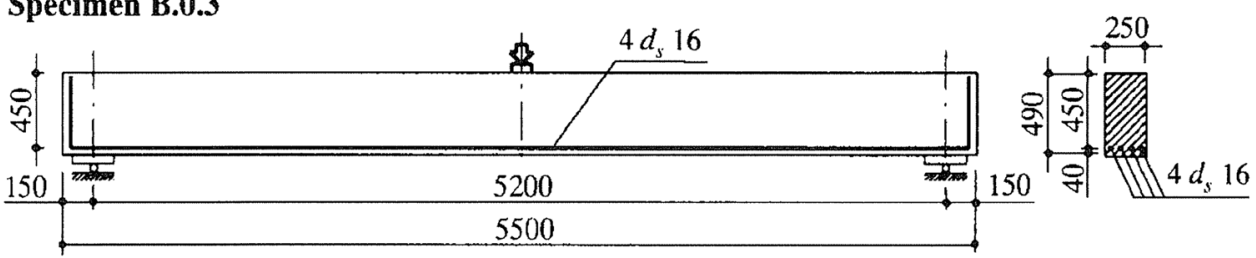

\begin{tabular}{|c|c|c|c|c|c|c|c|c|c|}
\hline \multirow[t]{2}{*}{ Code } & \multicolumn{3}{|l|}{ Size } & \multicolumn{3}{|c|}{ Concrete } & \multicolumn{3}{|l|}{ Steel } \\
\hline & $\mathrm{d}(\mathrm{mm})$ & $\mathrm{B}(\mathrm{mm})$ & $\mathrm{L}(\mathrm{mm})$ & $f_{c}^{\prime}(\mathrm{MPa})$ & $f_{c t}(\mathrm{MPa})$ & $\rho_{s}(\%)$ & $f_{t}(\mathrm{MPa})$ & $f_{y}(\mathrm{MPa})$ & $\varepsilon_{t}(\%)$ \\
\hline B.01.1.4 & 90 & 50 & 1000 & 31.71 & 2.47 & 0.28 & 678 & 590 & 3.6 \\
\hline B.0.2.4 & 180 & 100 & 2000 & 34.4 & 2.37 & 0.279 & 641 & 562 & 9.17 \\
\hline B.0.2.16 & 180 & 100 & 2000 & 40.57 & 3.16 & 0.279 & 641 & 562 & 9.17 \\
\hline B.0.3.4 & 450 & 250 & 5200 & 33.52 & 2.31 & 0.279 & 641 & 568 & 9.36 \\
\hline B.0.3.16 & 450 & 250 & 5200 & 37.25 & 2.77 & 0.279 & 641 & 568 & 9.36 \\
\hline B. 1.1.4 & 90 & 50 & 1000 & 33.12 & 2.51 & 1.118 & 641 & 562 & 9.17 \\
\hline B. 1.2.4 & 180 & 100 & 2000 & 35.27 & 2.33 & 1.117 & 661 & 573 & 9.31 \\
\hline B. 1.2 .16 & 180 & 100 & 2000 & 39.76 & 2.91 & 1.117 & 661 & 573 & 9.31 \\
\hline B. 1.3.4 & 450 & 250 & 5200 & 32.26 & 2.26 & 1.116 & 650 & 550 & 9.27 \\
\hline B. 1.3 .16 & 450 & 250 & 5000 & 35.43 & 2.73 & 1.116 & 650 & 550 & 9.27 \\
\hline
\end{tabular}




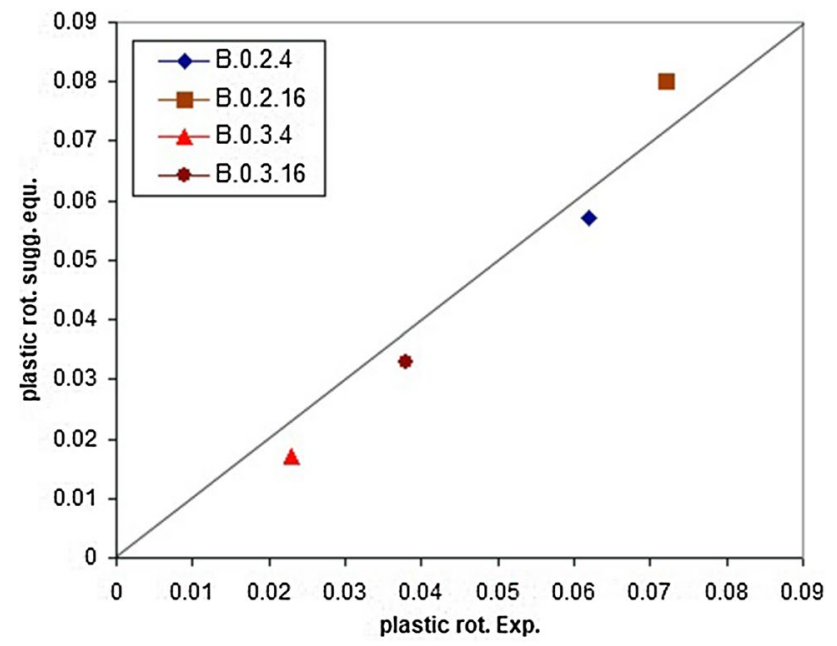

Fig. 12 Comparison of plastic rotation capacity between the suggested simplified equation and measuring experimentally for steel ratio $0.27 \%$

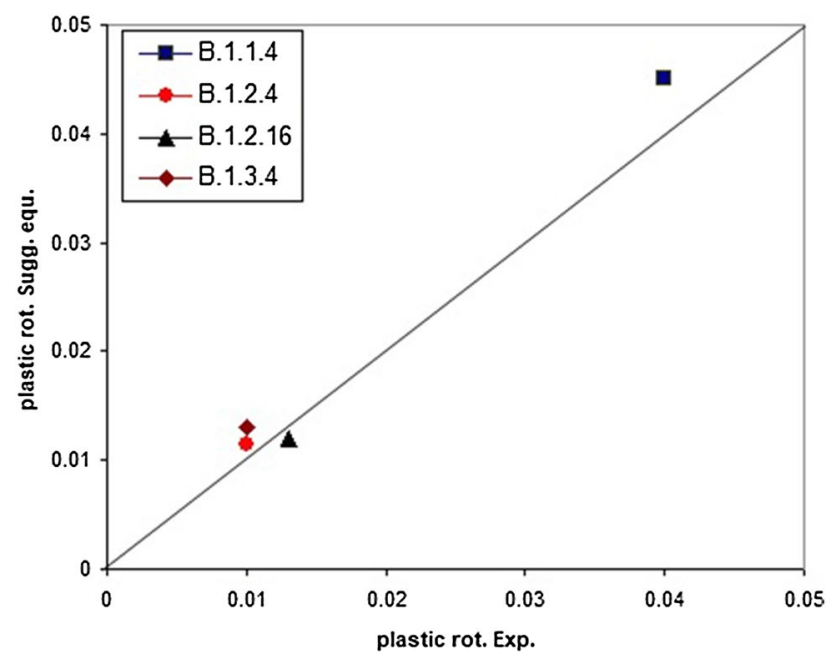

Fig. 13 Comparison of plastic rotation capacity between the suggested simplified equation and measuring experimentally for steel ratio $1.12 \%$

the plastic rotation capacity will be computed and compared with the experimental results. The comparison is shown in Figs. 12 and 13.

The comparison illustrated that the efficiency of the suggested equation as a simple formulation is acceptable. The suggested equation takes into account a lot of factors such as reinforcement ratios, member size and concrete and steel types. Based on this equation, the behavior of the beams by the load deflection curve can be predicted as shown later.

\section{Mathematical model to compute the plastic deformations}

The deformations of the beam after crack till yielding can be computed based on linear analysis, where the moment of inertia for the cross section in this stage can be replaced with cracking moment of inertia in virtual section, and using the same linear equations of the structural analysis. After yielding where clearly changing of modules of elasticity and the moment of inertia at the plastic zone as increasing the load, the deformations will be more difficult to determine. The deformations which occurred after yielding are computed by analytically using programs take into consideration materials nonlinearity or measuring experimentally. In this study, simple mathematical model will be suggested to compute the plastic deformations avoiding the complexity of materials nonlinearity.

Figure 14 shows the curvature through the half span of the previous analyze beam (1) with increasing the load after the yield till ultimate load. It is clear that the curvature through the yield zone as the load increases can be considered as linearly, and in similar to the all beams. So, the plastic rotation at any stage of loading can be formulated generally as

$\theta_{p}=\frac{1}{2}\left(\varphi-\varphi_{y}\right) \cdot l_{y}$

where $\varphi$ the curvature of middle section at any step of loading

$I_{y}=\frac{M-M_{y}}{M} \cdot \frac{L}{2}=\frac{\Delta M}{M} \cdot \frac{L}{2}$

$M$ is the bending moment of the middle section at any step of loading.

Equation (35) can be rewritten as

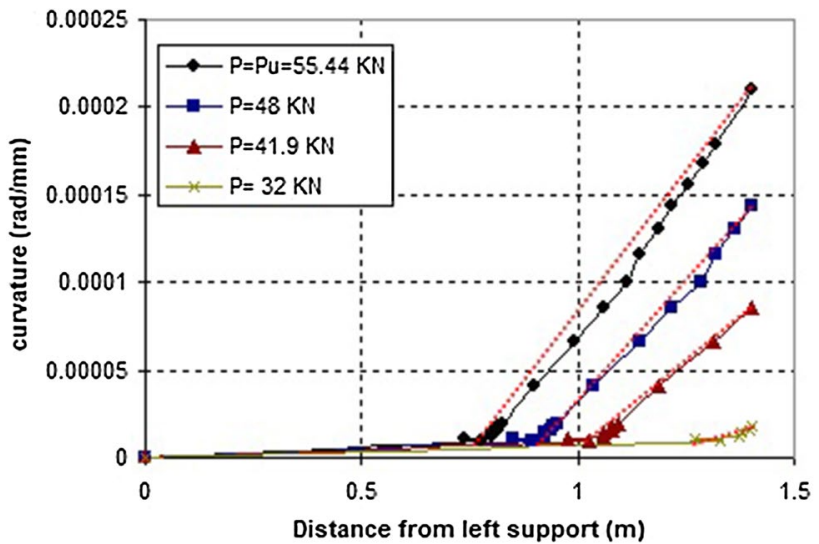

Fig. 14 The curvature in the yield length at different loading steps 


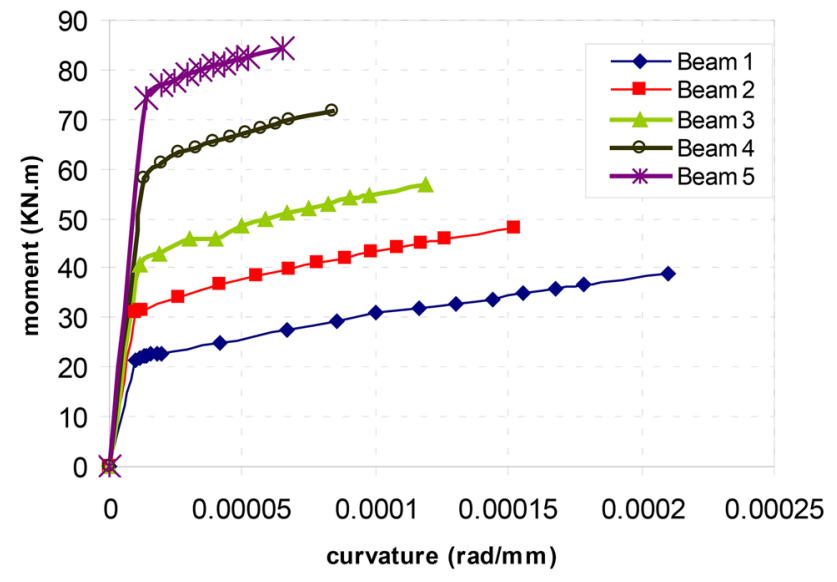

Fig. 15 The moment-curvature relationship of the analyzed beams

$\theta_{p}==\frac{L}{4}\left(\varphi-\varphi_{y}\right) \frac{\Delta M}{M}$

By Eq. (36), the plastic rotation at any loading step can be calculated.

Figure 15, shows the relationship between the moment and curvature of the previous analyzed beams $(1,2,3,4$ and 5), it was observed clearly that

$\frac{\varphi-\varphi_{y}}{M-M_{y}}=\frac{\varphi_{u}-\varphi_{y}}{M_{u}-M_{y}}=$ const.

Equation (36) can be rewritten as

$\theta_{p}=\frac{L}{4} \frac{\left(\varphi-\varphi_{y}\right)}{\Delta M} \cdot \frac{\Delta M^{2}}{M}$

Substituting Eq. (37) into Eq. (38), the last equation becomes as

$\theta_{p}=\frac{L}{4} \frac{\left(\varphi_{u}-\varphi_{y}\right)}{\Delta M_{u}} \cdot \frac{\Delta M^{2}}{M}$

const. $=\frac{1}{K_{\theta}}=\frac{L}{4} \cdot \frac{\left(\varphi_{u}-\varphi_{y}\right)}{M_{u}-M_{y}}, \quad M^{*}=\frac{\Delta M^{2}}{M}$

The plastic rotation capacity at any loading step can be formulated as

$\theta_{p}=\frac{M^{*}}{K_{\theta}}$

Hence, it is easy to compute the plastic rotation at any stage of loading not only at the failure stage. This helps to use the linear analysis to determine the plastic deformations after the yield till failure. The RC beam can be modeled after the yield by representing the plastic zone as intermediate hinge with rotational spring. This spring has a rotational stiffness $K_{\theta}$ which can be computed based on Eq. (40).

The plastic deflection of the beam after yielding can be represented in the suggested model as the deflection due to rotation of the rotational spring. This deformation can be calculated easy as the following

$W_{e}=W_{i}$

External virtual work = internal virtual work

$1 * \delta_{p}=\Delta \theta_{p} * M^{\prime}$

where $\delta_{p}$ is plastic deformation, $\Delta \theta_{p}$ the relative plastic rotation is equal to $2 \theta_{p}$ due to the symmetry, $M^{\prime}$ is the bending moment at mid span due to the existence of unit force and equal to $L / 4$

$\delta_{p}=2 * \frac{M^{*}}{K_{\theta}} * \frac{L}{4}$

$\delta_{p}=2 * \frac{\Delta \varphi_{u}}{\Delta M_{u}} * \frac{\Delta M^{2}}{M} * \frac{L}{4} * \frac{L}{4}$

$\delta_{p}=\frac{\Delta \varphi_{u}}{\Delta M_{u}} \cdot \frac{\Delta M^{2}}{M} \frac{L^{2}}{8}$

Hence, the final deformation at any stage of loading after the yield is divided into two terms as follows in Eq. (47). The modeling of yielding zone is shown in Fig. 16.

$\delta=\delta_{e l}+\delta_{p}$

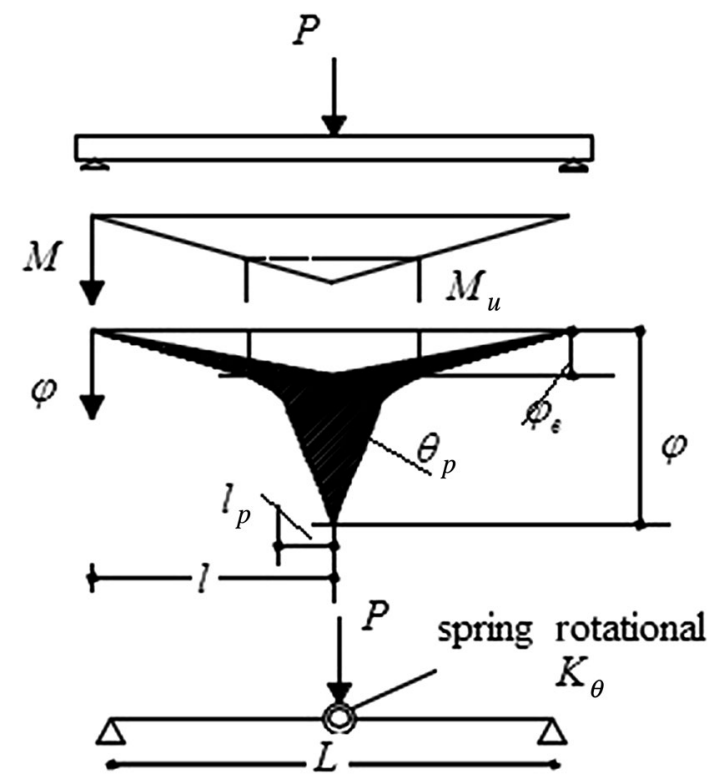

Fig. 16 Modeling of yielding zone 
Fig. 17 Details of tested beams

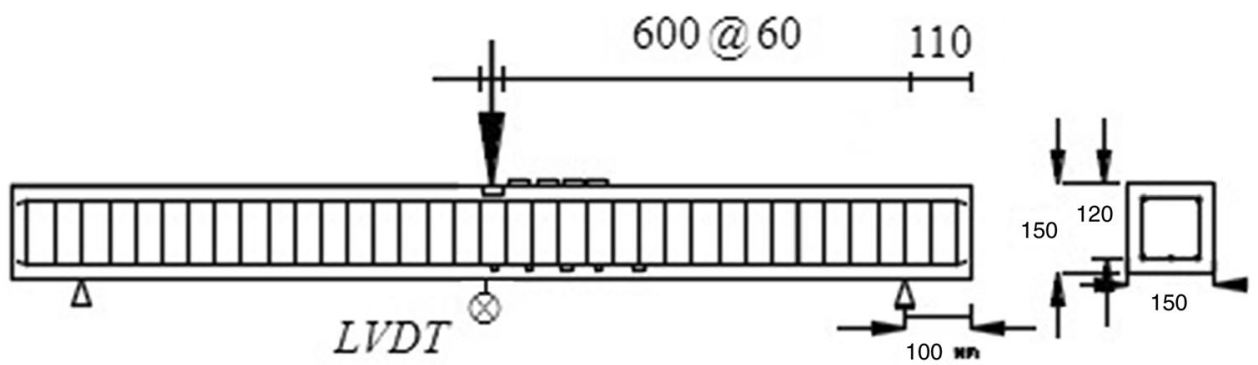

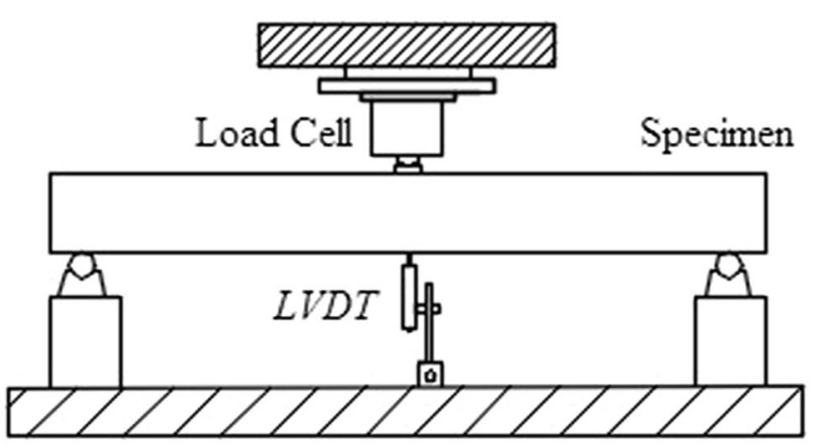

Fig. 18 Test set up for beams

where $\delta_{e l}=\frac{p I^{3}}{48 E_{c} I_{c r}}$

\section{Verified the mathematical model experimentally}

Four simply supported beams were experimentally tested under middle concentrated load will be analyzed by the suggested mathematical model to verify it. The load deflection curves of the four tested beams were as a part of experimental work made by Ko et al. [17] to study the plastic rotation capacity. The details of the beams are shown in Figs. 17, 18. A comparison of the load deflection curve between the mathematical model and the experimental results will be preceded and shown in Fig. 19a-d.

The properties of tested beams are shown in Table 3.

The notations for beam designations are as follows:

6-30-1 where 6: compressive strength of concrete $(60 \mathrm{MPa}),(30)$ : tension reinforcement ratio and (1): loading type "1-point loading".

The properties of the steel reinforcement are shown in Table 4, the ultimate concrete compressive strain is calculated according to the following equation $\varepsilon_{c u}=0.003+1.44 \frac{1}{\left(f_{c}^{\prime}\right)^{2}}+0.00054\left(\frac{\rho^{\prime}}{\rho_{s}}\right)$

It was observed from the shown load deflection curves in Fig. 19a-d, that the mathematical model gives matching results comparing to the results of experimental tests. As a result, this mathematical model can be used in future work in computing moment redistribution of indeterminate R.C beams.

\section{Conclusions}

The following conclusions have been drawn out of the presented study:

A simplified equation was suggested in this research to compute plastic rotation capacity in R.C beams. The tension and compression reinforcement ratios, materials strengths, member geometry which are as affected parameters were included in this equation. By analytical programs and previous experimental studies, the simplified equation was verified and the results were satisfying.

To ease the way to compute the plastic rotation of R.C beams, that wasn't the main destination of the research. A structural mathematical model based on the simplified equation was as a main aim of the research and suggested to compute the plastic deformations of R.C beams. This model can be used to compute the plastic deformations from yielding till the ultimate moment, wasn't only at the ultimate moment as in various common formulations. In the suggested model, the yielding zone was represented as intermediate hinge with rotational spring. The rotational stiffness of the spring was computed according to the suggested simplified equation. The mathematical model was verified by analyzing tested simply supported beams with various parameters. A comparison of the load deflection curves between the results of the tested beams and the mathematical model, illustrated that the results were matching each other. The simplified mathematical analysis which was presented 


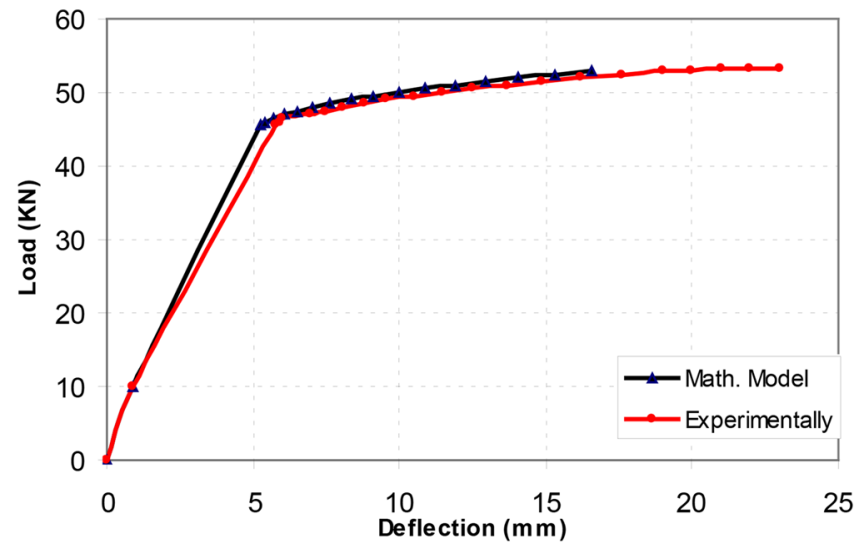

(a) Beam 6-30-1

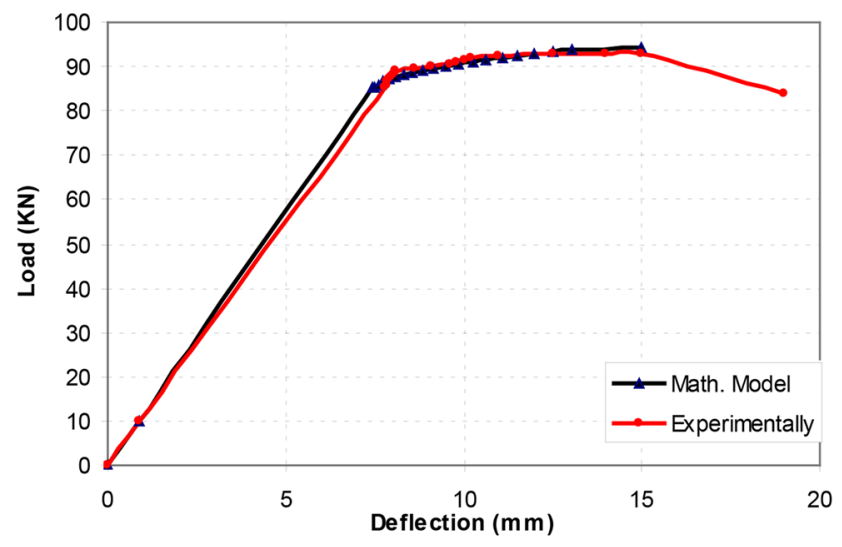

(c) Beam 6-65-1

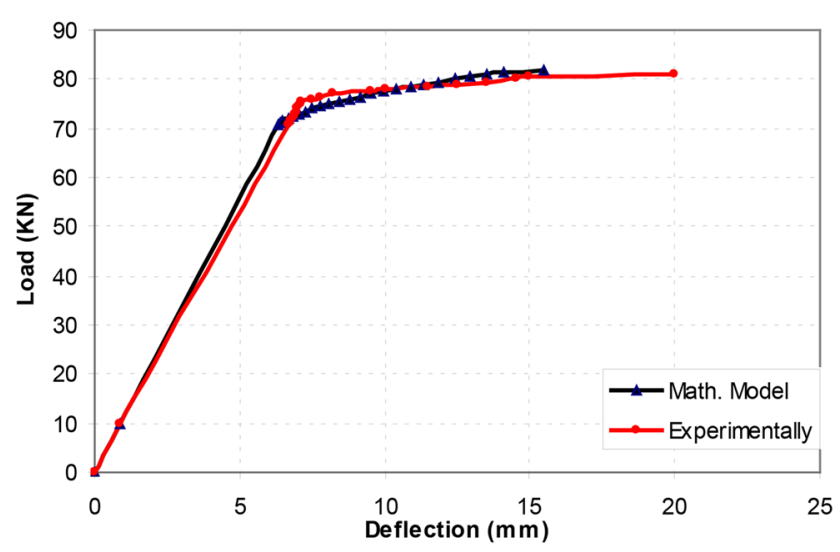

(b) Beam 6-50-1

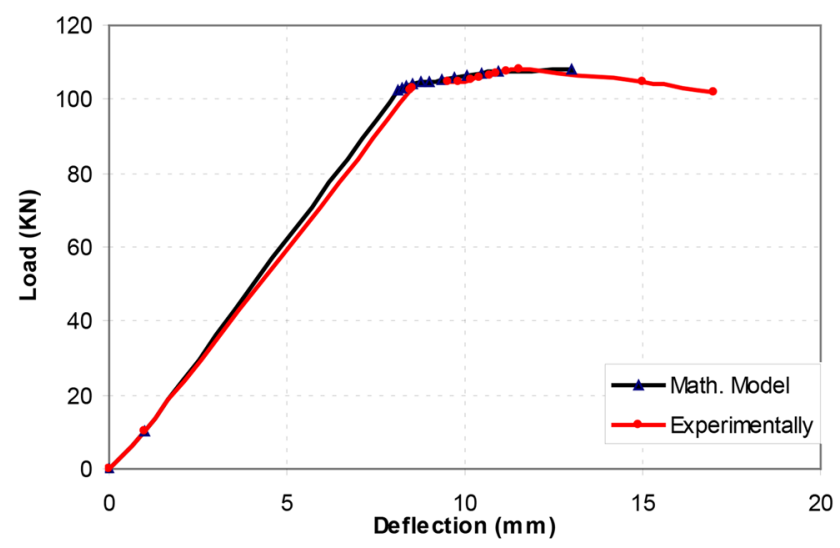

(d) Beam 6-75-1

Fig. 19 Comparison of load deflection curve of the tested beams between the mathematical model and experimental measure

Table 3 Properties of tested beams

\begin{tabular}{lllll}
\hline No. & Beams & \multicolumn{2}{l}{ Steel details } & $f_{c}^{\prime}$ \\
\cline { 3 - 4 } & & Numbers of bars & $\rho / \rho_{b}$ & \\
\hline 1 & $6-30-1$ & 2D13-1D10 & 0.33 & 66.6 \\
2 & $6-50-1$ & 2D16-1D13 & 0.54 & 66.6 \\
3 & $6-65-1$ & 2D19-1D10 & 0.66 & 66.6 \\
4 & $6-75-1$ & 2D19-1D16 & 0.79 & 66.6 \\
\hline
\end{tabular}

Table 4 Properties of reinforcement steel

\begin{tabular}{lllll}
\hline Bar size & Area $\left(\mathrm{cm}^{2}\right)$ & $\begin{array}{l}\text { Yield } \\
\text { strength } \\
(\mathrm{MPa})\end{array}$ & $\begin{array}{l}\text { Tensile } \\
\text { strength } \\
(\mathrm{MPa})\end{array}$ & $\begin{array}{l}\text { Elastic } \\
\text { modulus } \\
(\mathrm{GPa})\end{array}$ \\
\hline D10 & 0.71 & 406 & 608 & 175 \\
$\mathrm{D} 13$ & 1.27 & 413 & 579 & 200 \\
D16 & 1.99 & 443 & 640 & 172 \\
D19 & 2.87 & 419 & 615 & 174 \\
D22 & 3.87 & 385 & 588 & 172 \\
\hline
\end{tabular}

in this work can be used in future work in computing moment redistribution of indeterminate R.C beams.

Acknowledgements We thank our colleagues from Delta University for Science and Technology who provided insight and expertise that greatly assisted the research, although they may not agree with all of the conclusions of this paper.

\section{Compliance with ethical standards}

Conflict of interest On behalf of all authors, the corresponding author states that there is no conflict of interest.

\section{References}

1. Bigaj A, Walraven $J$ (2002) Size effects in plastic hinges of reinforced concrete members. HERON 47(1):53-75

2. Kheyroddin A, Naderpour $\mathrm{H}$ (2007) Plastic hinge rotation of reinforced concrete beams. Int J Civ Eng 5(1):30-47 
3. Arslan G, Cihanli E (2010) Curvature ductility prediction of reinforced high-strength concrete beam sections. J Civ Eng Manage 16(4):462-470

4. Baker ALL, Amarakone AMN (1964) Inelastic hyper static frames analysis. In: Proceedings of the international symposium on flexural mechanics of reinforced concrete, Miami, Florida, ASCE 1965-50, ACISP-12, pp 85-142

5. Bernardo LFA, Lopes SMR (2004) Neutral axis depth versus flexural ductility in high-strength concrete beams. ASCE J Struct Eng 130(3):452-459

6. Bosco C, Carpinteri A, Debernardi PG (1992) Scale effect on plastic rotational capacity of R. C beams. In: Fracture mechanics of concrete structures, the first international conference of concrete structures, Breckenridge

7. Carmo RNF, Lopes SMR (2008) Available plastic rotation in continuous high-strength concrete beams. Can J Civ Eng 35:1152-1162

8. Carmo RNF, Lopes SMR (2005) Ductility and linear analysis with moment redistribution in reinforced high-strength concrete beams. Can J Civ Eng 32:194-203

9. Carreira D, Chu K-H (1985) Stress-strain relationship for plain concrete in compression. ACl J 82(6):797-804

10. Cederwall K, Sobko W (1990) The size effect of the rotational capacity of reinforced concrete beams, an experimental study, nordic concrete research meeting, Trondheim

11. Corley WG (1966) Rotation capacity of reinforced concrete beams. Proc ASCE Struct J 92(ST-4):121-146

12. Desayi P, Krishnan S (1964) Equation for the stress-strain curve of concrete. ACI J 61(3):345-350

13. Ezeldin AS, Balaguru PN (1992) Normal- and high-strength fiber-reinforced concrete under compression. J Mater Civ Eng 4(4):415-429

14. Hilierbogr A (1989) Fracture mechanics concept applied moment capacity and rotational capacity of reinforced concrete beams. In: International conference on fracture and damage of concrete and rock, Vienna

15. Hilierbogr A (1989) The compression stress-strain curve for design of reinforced concrete beams. Fract Mech Appl Concr $\mathrm{SP}-118, \mathrm{ACl}$

16. Markeset $G$ (1993) Failure of concrete under compression strain gradients. Ph.D. thesis 1993:110, The Norwegain Institute of Technology, Trondheim

17. Ko Y, Kim S-W, Kim J-K (2001) Experimental study on the plastic rotation capacity of reinforced high strength concrete beams. Mater Struct/Materiaux et Constructions 34:302-311

18. Mattock AH (1965) Rotational capacity of hinging regions in reinforced concrete beams, flexural mechanics of reinforced concrete, ASCE

19. Mattock AH (1964) Rotational capacity of hinging regions in reinforced concrete beams. In: Proceedings of the international symposium on flexural mechanics of reinforced concrete, Miami, Florida, ACI SP-12, pp 143-181

20. Nataraja MC et al (1999) Stress-strain curves for steel-fiber reinforced concrete under compression. Cem Concr Compos 21:383-390

21. Riva P, Cohn MZ (1994) Rotation capacity of structural concrete members. Mag Concr Res 46(168):223-234

22. Saenz LP (1965) Equation for the stress-strain curve of concrete in uniaxial and biaxial compression of concrete. $\mathrm{ACl} J$ 61(9):1229-1235

23. Smith GM, Young LE (1956) Ultimate flexural analysis based on stress-strain curves of cylinders. ACI J 53(6):597-610

Publisher's Note Springer Nature remains neutral with regard to jurisdictional claims in published maps and institutional affiliations. 